\title{
STUDIO MEDIA VISUAL DAN SINEMA RUANG LUAR MELAWAI
}

\author{
Maudy Maharani ${ }^{1}$, Lina Purnama ${ }^{21}$ \\ 1) Program Studi S1 Arsitektur, Fakultas Teknik, Universitas Tarumanagara, xmaudymaharanix@hotmail.com \\ 2) Program Studi S1 Arsitektur, Fakultas Teknik, Universitas Tarumanagara, linapurnama.112@gmail.com
}

\begin{abstract}
Abstrak
Media merupakan salah satu unsur yang bertanggung jawab atas penyebaran informasi ditengah masyarakat modern. Proyek Studio Media Visual dan Sinema Ruang Luar Melawai merupakan respon atas fenomena multikultur yang disebabkan oleh pluraritas masyarakat yang tinggi di kawasan tersebut. Tujuannya adalah untuk mengembalikan kembali nilai-nilai lokal yang kabur ditengah derasnya arus pengaruh dari budaya asing. Selain itu, proyek juga berperan sebagai pemererat hubungan antar masyarakat Melawai dalam asas komunitas melalui usaha dalam menumbuhkan rasa kebanggaan tidak hanya terhadap karya asing namun juga karya anak bangsa, melalui konsep dan program yang ditawarkan. Dengan sinergi terhadap proyek M-Bloc space yang merupakan kerja sama antara PERURI dengan badan swasta guna menciptakan ruang kreatif sebagai meeting point yang terintegrasi dengan Halte MRT Sisingamangaraja dan Halte MRT Blok-M, proyek Studio Media Visual dan Sinema Ruang Luar ikut berkontribusi dalam meningkatkan kualitas masyrakat secara sosial, ekonomi maupun budaya melalui kegiatan kreasi dan apresiasi karya. Konsep kreasi dan apreasiasi juga dijadikan sebagai dasar atas program dan penempatan ruang, dimana Sinema Ruang Luar berperan sebagai pusat (apresiasi) dan studio pre-produksi, produksi, dan pos- produksi yang mengegelilinginya. Program street- sport zone juga dihadirkan sebagai ruang netral yang diharapkan dapat menarik pengunjung baru diluar komunitas dengan minat yang sama, juga memicu kreatifitas komunitas melalui stimulasi pikiran melalui gerak fisik. Metode yang digunakan merupakan pendekatan kontekstual yang mengkaji empat parameter kontekstual (budaya, alam, urban, dan fisik bangunan) yang menghasilkan bentuk yang eksploratif namun tetap menyisikpkan unsur- unsur kolonial yang merupakan wujud bangunan dari kompleks Eks- PERURI dan M-Bloc Space.
\end{abstract}

Kata kunci: budaya; kreatif; media visual; melawai

\begin{abstract}
The media is one among many other factors, that is responsible for the dissemination of information amidst modern society. The Melawai Visual Media Community Studio and Open- Cinema project is created as a response towards the multicultural phenomenon caused by high plurarity rate of residents coming from different regions, locally or internationally. It aims to restore local values that starts to becoming insignificant among rapid globalization that is happening in the area. In addition, it also plays a role in strengthening relations between community-based social circles through efforts to foster a sense of pride towards local creative products. Synergized with M-Bloc Space which is a collaboration between PERURI and local creative industries intended to provide a space for creative-based community as a meeting point that is intergrated with Sisingamangaraja MRT Stop and Blok-M MRT Stop, Visual Media Community Studio and Open-Cinema project helps to upgrade the quality of the residents socially, economically and culturally through Creation and Appreciation program. The concept of Creation and Apreciation is the sole base of reference to determine the placement of programs on site, as the Open-Cinema (apreciation) placed in the center, supported by Pre-productions, Productions, and PostProductions programs (creation) which revolves around it. The Street-sport zone program is also presented as a neutral space that is expected to attract new visitors outside visual media community, also to contribute in supporting the creativity programs through
\end{abstract}


stimulation of mind through physical movement. The method used for this project's design is examining several important contextual parameters around the area (cultural, nature, urban, and buildings' form) as to produce a form that is explorative but still possess the soul of Colonial Architecture used in the remain buldings of PERURI and M-Bloc Space through the use of vertical elements and the minimalism of material chosen for the building.

Keywords: creative; culture; melawai; visual media

\section{PENDAHULUAN}

\section{Latar Belakang}

Kawasan Blok M, CSW, dan Melawai merupakan kawasan yang sejarahnya dillatar belakangi oleh kegiatan berkumpul dan bersosialisasi di satu tempat tertentu. Sebuah melting pot yang menawarkan berbagai hiburan kesenian dan budaya sebagai daya tarik kawasan tersebut kian redup seiring semakin ketatnya persaingan dengan kawasan- kawasan meeting spot lain yang lebih hip dan mudah dijangkau. Wadah masyarakat akan ruang terbuka kreatif kian hilang, membuat kawasan kehilangan nafasnya sebagai pusat kegiatan yang tidak pernah redup. Hal ini berpengaruh terhadap perkembangan kesejahteraan masyarakat, baik secara sosial, ekonomi, maupun budaya. Maraknya pengaruh dari budaya yang dibawa oleh ekspat-ekspat asing menggeser nilai-nilai lokal yang seharusnya dianut oleh kawasan tersebut. Namun, dengan rampungnya pembangunan fasilitas MRT di tahun 2019 yang memudahkan akses terutama bagi para pekerja di pusat kota, kawasan mendapatkan kesempatan kedua untuk ikut berpartisipasi dalam penanaman budaya lokal serta pengembangan pribadi masyarakat melalui peleburkan budaya lokal dengan budaya asing dalam bentuk ekspresi produk seni yang menyatukan kembali masyarakat melalui kebanggaan nya akan kreasi Tanah Air.

Cliffort Geertz memandang kebudayaan sebagai perangkat mekanisme kendali untuk mengatur kelakuan ${ }^{1}$. Secara historis, pluraritas masyarakat yang tinggi di daerah Melawai melatarbelakangi fenomena masyarakat multikultur yang menjadikan Melawai sebagai sebuah melting pot, sebuah lokasi dimana kesenian dan kebudayaan bertemu menjadi satu. Sebagai salah satu pelopor lokasi sosial dan hiburan, dampak fenomena multikultur tersebut memberikan pengaruh besar terhadap kesejahteraan masyarakat, baik secara sosial, ekonomi, maupun budaya. Pengaruh kebudayaan asing tidak hanya ditularkan secara langsung melalui pertukaran informasi antar dua individu yang bertatap muka, namun juga lewat sarana media informasi, khususnya media visual, yang memegang peranan besar didalam suatu perubahan yang terjadi terhadap masyarakat informasi. Maraknya pengaruh dari budaya yang terutama dibawa oleh kalangan masyarakat asing yang bertempat di Melawai merupakan kesempatan yang dapat dijadikan sebagai media pembelajaran secara seni dan budaya. Proyek ini bertujuan untuk mengikat kembali masyarakat dalam asas komunitas yang berdampak positif terghadap simbiosis diantara anggotanya, melalui penanaman kembali nilai-nilai lokal yang ditanamkan kedalam produk media visual yang dihasilkan, dan menumbuhkan rasa kebanggaan kembali sebagai masyarakat satu rumpun suku bangsa dengan ikut mengkreasikan dan mengapresiasikan karya industri lokal. Berangkat dari peluang yang ada, proyek ini menawarkan program dan fasilitas yang dapat digunakan sebagai media yang memudahkan insan-insan kreatif dalam upaya mereka dalam mengeksplorasi kesenian dan kebudayaan, khususnya dalam media visual.

Industri kreatif sendiri menurut Kementrian Perdagangan Indonesia adalah industri yang berasal dari pemanfaatan aktifitas, ketrampilan, serta bakat individu untuk menciptakan kesejahteraan serta lapangan pekerjaan dengan menghasilkan dan mengeksploitasi daya kreasi dan daya cipta individu tersebut. Seni yang mendominasi sector-sektor industry kreatif memiliki berbagai kegiatan yang harus diwadahi seperti kegiatan jual-beli (pemasaran), gelar karya (pameran), dan lokakarya (workshop) sebagai sosialisasi dan sarana komunikasi antar pengguna.

\footnotetext{
${ }^{1}$ Geertz, Clifford (2017). Interpretation of Culture. New York: Paperback
} 
Menurut BEKRAF, kontribusi industri kreatif ke PDB 2018 berupa lebih dari Rp. 1.000 Trilliun sedangkan pada akhir tahun 2016 sudah menyumbangkan Rp. 922 Trilliun. ${ }^{2}$ Berbagai pencapaian tersebut menambah optimisme bahwa industri kreatif bisa menjadi mesin penggerak ekonomi terbaru di Indonesia di masa mendatang. Selain itu, terdapat anggapan yang menyatakan bahwa peningkatan terhadap industri kreatif paling baik ditempuh melalui asas kolaborasi. Oleh karena itu, perancang bermaksud untuk meningkatkan fungsi program alihfungsi perum PERURI sebagai pusat wadah ruang kreatif dengan mempertahankan sinergi yang dimiliki oleh M-bloc Space terhadap proyek rancangan. Hal ini berpengaruh terhadap pemilihan media visual sebagai program utama proyek untuk dapat mendukung program M-bloc Space yang kian bergerak di ranah industri kreatif permusikan.

\section{Rumusan Permasalahan}

Pada survey yang dilaksanakan oleh BEKRAF pada tahun 2015, besaran PDB ekonomi kreatif mengalami kenaikan rata-rata $10,14 \%$ setiap tahunnya, yaitu dari Rp. 525.96 trilliun menjadi Rp. 852.24 trilliun dengan dominasi didalam subsektor industri kreatif kuliner, fesyen, dan kriya. Subsektor yang menempati urutan terbawah merupakan industri film dan industri desain komunikasi visual. ${ }^{3} \mathrm{Di}$ sisi lain, subsektor film dan desain komunikasi visual merupakan 2 subsektor yang memiliki pertumbuhan paling pesat sebanyak $10,28 \%$ diantara subsektor lainnya. Dari hal ini dapat disimpulkan beberapa hal yang perlu diperhatikan seperti:

a. Kurangnya wadah yang memfasilitasi pekerja subsektor industri kreatif film dan desain komunikasi visual

b. Kebutuhan untuk peningkatan kualitas terhadap produk film dan desain komunikasi visual yang didukung oleh edukasi yang memadai dan sumber daya manusia yang berkualitas

c. Monopoli terhadap wadah apresiasi pasar yang didominasi oleh karya asing

d. Rendahnya apreasiasi masyarakat terhadap karya lokal

\section{Tujuan}

a. Menyediakan wadah fisik kreasi dan apresiasi yang mendukung perkembangan industri kreatif serta berkontribusi dalam menyalurkan jati diri dan karakter masyarakat sekitar sebagai bentuk apresiasi terhadap keistimewaan yang dimiliki oleh masing- masing individu

b. Mengedukasi masyarakat terhadap potensi industri kreatif yang dapat meningkatkan kesejahteraan ekonomi dan merubah stigma negatif masyarakat terhadap industri kreatif

c. Menengahi fenomena maraknya budaya asing ditengah masyarakat Jakarta dan menanamkan kembali nilai-nilai lokal serta berfungsi sebagai 'filter kebudayaan' yang mengurangi dampak negatif dari globalisasi

d. Menginklusi kaum dengan keterbatasan tertentu (disabilitas, putus sekolah) dengan memberi perlakuan dan hak yang sama dan mengapresiasi mereka sebagai bagian dari masyarakat

\section{KAJIAN LITERATUR}

\section{Open Architecture: Third Space}

Ray Oldenburg didalam bukunya The Great Good place menyatakan bahwa Third Place merupakan pengaturan inti dalam kehidupan publik informal dan memegang peranan sebagai pembentuk ruang interaksi sosial. Pengertian singkatnya adalah sebagai suatu tempat yang biasa dijadikan tempat berlindung sementara dari kebosanan rutinitas dimana

\footnotetext{
${ }^{2}$ Wawancara dengan Triawan Munaf (Kepala Badan Ekonomi Kreatif), tanggal 1 Agustus 2018 di Plaza Senayan Jakarta.

${ }^{3}$ BEKRAF. (8/01/2019). Dalam artikel yang berjudul Kontribusi PDB Ekonomi Kreatif Menurut Subsektor.
} 
orang akan mendapatkan ketenangan dan kesenangan didalamnya. Third Place merupakan destinasi yang diperuntukan bagi pertemuan antar individu yang bersifar reguler, sukarela, informal, dan diantisipasi oleh khalayak ramai diluar ranah rumah dan pekerjaan. Karakteristik Third Place didefinisikan sebagai:

- Representasi dari pengalaman personal

- Kebutuhan individual yang terpenuhi

- Menegaskan jati diri (who we are and what we do)

- Fungsional

- Ada saat dibutuhkan (real, bukan virtual)

\section{METODE}

Penelitian ini mengkaji strategi dan aplikasi dalam perancangan proposal proyek yang bertujuan untuk mengetahui strategi dan aplikasi pendekatan kontekstual (Renzo Piano) yang ditinjau dari empat parameter kontekstual, yaitu: pendekatan budaya (cultural respect) dalam skala makro, pendekatan alam (nature) dalam skala messo, pendekatan urban (urban context) dalam skala messo, dan pendekatan fisik bangunan (physical respect) dalam skala mikro.

Adapun tujuan- tujuan yang ingin dicapai melalui melibatkan empat parameter ini:

\section{- Pendekatan budaya (Cultural Respect)}

Merespon fenomena multikultur yang menjadi permasalahan budaya utama yang terjadi pada kawasan Kebayoran Baru yang berada di Kota Metropolitan dengan tingkat pengaruh budaya asing yang intensif, yang berpengaruh terhadap kaburnya nilai- nilai lokal yang dianut oleh masyarakat setempat

- Pendekatan alam (Nature)

Rensponsivitas terhadap kondisi iklim kawasan dan penerapan green-architecture demi kelangsungan lingkungan sekitar, tapak yang berada dikawasan urban harus dapat berkontribusi terhadap kelangsungan lingkungan hijau dan tidak merusak alam

- Pendekatan urban (Urban-Context)

Penyelesaian karya dalam lingkup kota dengan melibatkan elemen- elemen infrastruktur dan elemen manusuia yang menjadi elemen pendukung pada proyek yang berpengaruh terhadap aksesibilitas dan pencapaian terhadap tapak, serta pertimbangan atas keragaman subjek tapak dalam hal usia, background ekonomi, dan kebutuhan- kebutuhan khusus

- Pendekatan fisik bangunan (Physical Respect)

Sebuah bentuk respon terhadap tapak yang lokasinya dikelilingi oleh bangunan konservasi kelas $\mathrm{C}$ yang memerlukan perhatian khusus dan juga untuk dapat bersinergi dengan elemen bangunan disekitarnya.

Berdasarkan kajian dan analisa yang dilakukan, dapat disimpulkan gambaran proyek yang akan dirancang serta kesinambungannya terhadap lokasi yang dipilih sesuai dengan tema yang ditentukan. Lokasi yang terpilih berada di Melawai, Jakarta Selatan karena sesuai dengan kriteria proyek dan isu yang telah dipilih. 

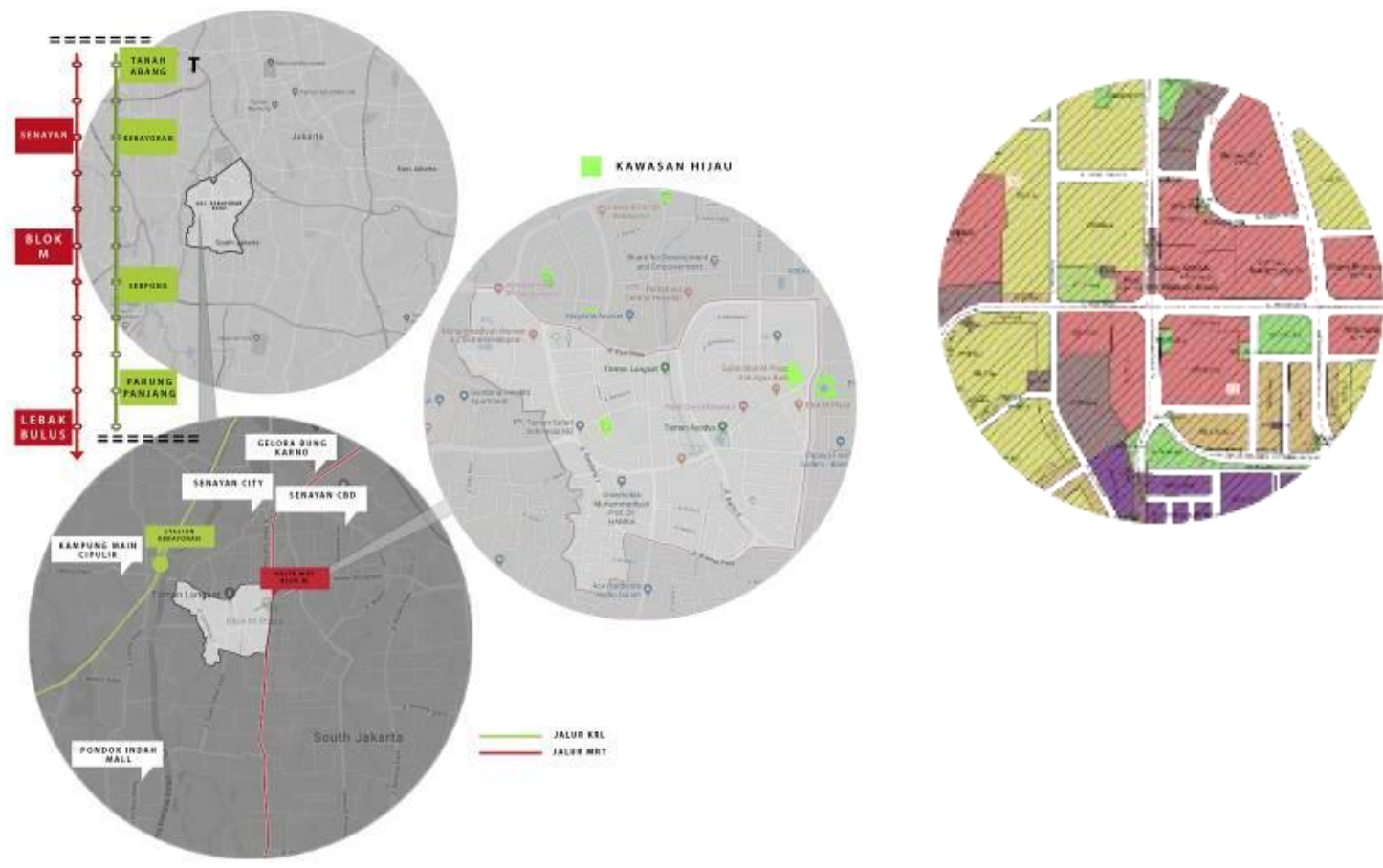

Gambar 1. Peta Lokasi Tapak Makro Sumber: Penulis, 2019

Pada survey yang dilkakukan, masyarakat usia produktif terbilang tinggi yaitu kisaran $53 \%$ dari total karyawan yang merupaka potensi insan- insan kreatif yang berkontribusi didalam proyek Studio Media Visual dan Sinema Ruang Luar. Melawai merupakan pilihan utama karena letaknya yang berada tidak jauh dari pusat kota, serta infrastruktur yang maju yang didukung oleh integrasi transportasi publik di sekitarnya (MRT, Transjakarta, dII). Lokasi tapak diberatkan dengan beberapa pertimbangan, sesuai dengan analisa parameter di sekitar lokasi tapak yang berupa:

a. Kedekatan Tapak dengan Titik Pusat Kegiatan

Kedekatan lokasi dengan daerah residensial berpotensi mengundang lebih banyak pengunjung karena berpotensi sebagai sebuah fasilitas komunal yang mengikat masyarakat dan mendorong terjadinya interaksi sosial yang lebih tinggi. Dengan perkembangan teknologi yang lebih maju, masyarakat cenderung mengandalkan gadget sebagai bentuk entertainment, hal itu menjadi salah satu alasan hilangnya gairah sosial dan terbentuknya individu yang tertutup, ketidak adaannya pertukaran pikiran, minim inspirasi dan hilangnya citra manusia sebagai mahkluk komunal. Dengan mendorong pembentukan curated communities ditengah zona residensial terutama residensial mewah, dipercaya dapat membantu membangun keragaman di dalam wilayah tersebut dan memerangi ketimpangan ekonomi maupun sosial.

- Praktik sosio-kultural

- Menggambarkan tantangan dan peluang dalam perancangan yang menitikberatkan terhadap keadilan dan inklusi-dengan pertimbangan transporasi, komodifik, aspek kehidupan nonpasar, stigmatisasi, dan isu pengucilan dari masyarakat yang kurang beruntung Kedekatan lokasi dengan lokasi perkantoran berpeluang untuk menjadikan projek sebagai 'tempat singgah' diantara First Place (rumah) dan Second Place (Kantor). Hal ini didukung oleh moda transportasi umum yang menghimpit lokasi diantara stasiun KRL. 


\section{b. Keberagaman background masyarakat}

Keberagaman background ekonomi didukung oleh letak geografis tapak yang dihimpit oleh pemukiman mewah dan kedekatannya dengan daerah ekonomi menengah (Cipulir, Joglo) berpotensi untuk mendatangkan pengunjung dari berbagai kalangan, dan mengikat mereka sebagai satu kesatuan dengan program- program yang ditawarkan oleh projek yang mengutamakan kebersahajaan, kebersamaan dan kenetralan antar individu.

\section{c. Akses yang Mudah}

Menurut Charles Montgomery dalam bukunya Happy City: Transforming Our Lives Through Urban Design, salah satu indikator 'kebahagiaan kota' adalah berupa transportability atau ketesediaan moda transportasi umum berkelanjutan dan menjamin mobilitas penduduknya ${ }^{4}$. Kelancaran pergerakan penduduk menjamin tercapainya semua tempat dan menjaga keberlansungan kegiatan- kegiatan di dalamnya. Sarana mobilitas pada lokasi lokasi terpilih didukung dengan keberadaan sarana transportasi umum berupa KRL yang berada di stasiun Kebayoran (5,2 KM dari lokasi terpilih) dan Stasiun MRT Asean (400m dari lokasi terpilih). Selain itu terdapat beberapa halte corridor yang tersebar di sekitar tapak termasuk Halte Koridor 13. Trafik pengguna kendaraan umum merupakan dari kaum komuter yang datang dari jalur KRL Serpong, yang menempati posisi ketiga dalam presentase aktivitas komuter terbanyak berdasarkan daerah asal (sumber: Jakarta.bps.go.id), maupun dari jalur Stasiun MRT daerah Jakarta Selatan (Lebak Bulus, Fatmawati, Cipete) yang berhendak menuju pusat kota untuk bekerja dalam kesehariannya. Jalur mobil utama berada pada Jalan Panglima Polim, Sisingamangaraja, Trunojoyo dan Kyai Maja yang didukung oleh fasilitas terminal bus Transjakarta Koridor 13 yang melayani rute Ciledug- Tendean.

Spesifikasi tapak ialah sebagai berikut:

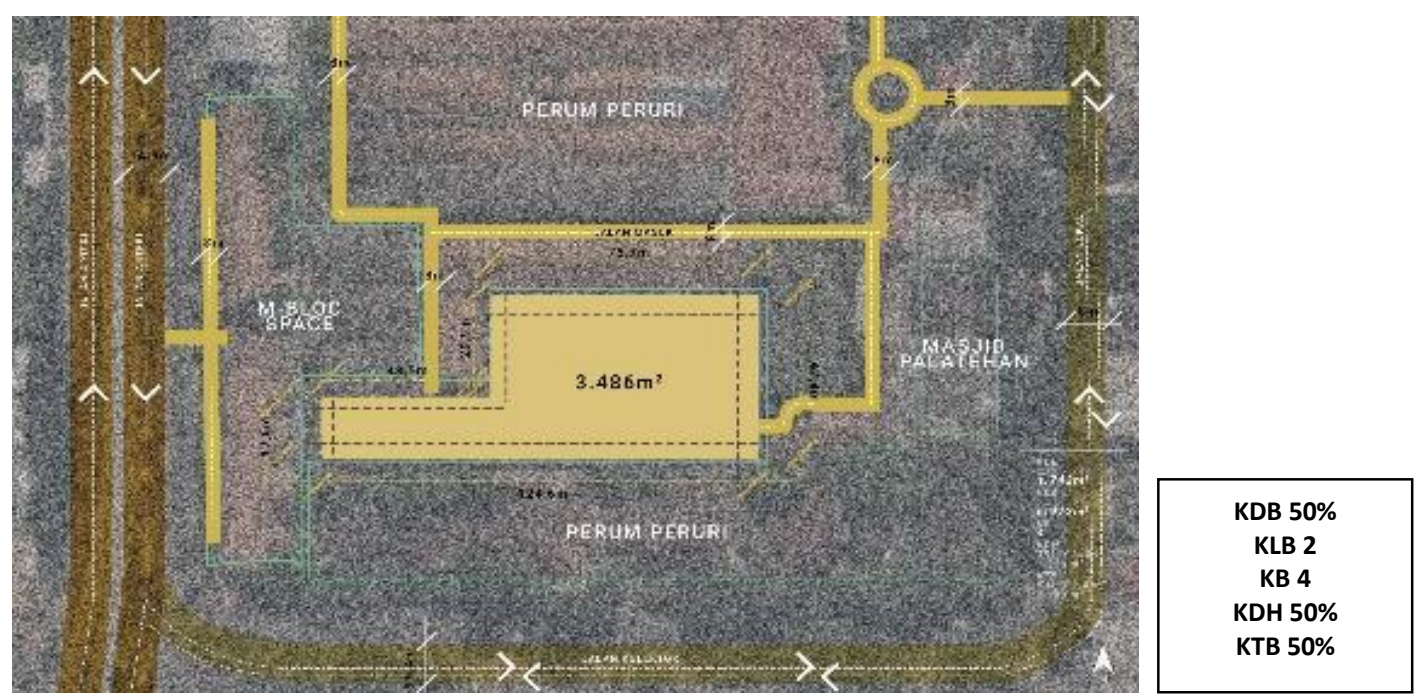

Gambar 2. Spesifikasi Tapak

Sumber: Data Pengembang

\footnotetext{
${ }^{4}$ Montgomery, Charles (2014). Happy City: Transforming Our Lives Through Urban Design. Amerika Serikat: Farrar, Straus, and Giroux
} 
Tabel 1. Hasil Analisa SWOT

\begin{tabular}{|c|c|}
\hline STRENGTH & $\begin{array}{l}\text { - } \text { Memiliki akses kendaraan umum yang mudah } \\
\text { - } \quad \text { Dekat dengan pusat kota dan memiliki fasilitas umum yang cukup } \\
\text { lengkap } \\
\text { - Cenderung strategis dan ramai pengunjung dan kepadatan } \\
\text { penduduk cukup tinggi }\end{array}$ \\
\hline WEAKNESS & - Harga tanah yang relatif mahal \\
\hline OPPORTUNITY & $\begin{array}{l}\text { - Merupakan wilayah yang cukup modern dan berkembang } \\
\text { sehingga pola pikir masyarakat generasi mudanya cukup open- } \\
\text { minded } \\
\text { - Memiliki demografi yang beragam sehingga dapat melibatkan } \\
\text { berbagai macam kalangan masyarakat dalam program } \\
\text { - Minim sarana entertainment yang tidak komersil (pusat } \\
\text { komunitas) }\end{array}$ \\
\hline THREAT & $\begin{array}{l}\text { - Berada ditengah kawasan jalur utama pengendara mobil yang } \\
\text { kian mengalami kemacetan pada jam- jam pergi-pulang kerja }\end{array}$ \\
\hline
\end{tabular}

Sumber: Pribadi

\section{DISKUSI DAN HASIL}

Masyarakat Jakarta merupakan masyarakat yang cenderung untuk lebih mudah mengikuti budaya asing ataupun yang bisa disebut sebagai fenomena globalisasi. Proses globalisasi membuat dunia menjadi borderless atau tanpa batas. Globalisasi yang menawarkan berbagai macam hiburan yang global berfungsi sekaligus juga sebagai medium tempat seseorang menemukan identitas dirinya didalam gaya hidup, budaya, dan nilai yang ditanamkan didalamnya.

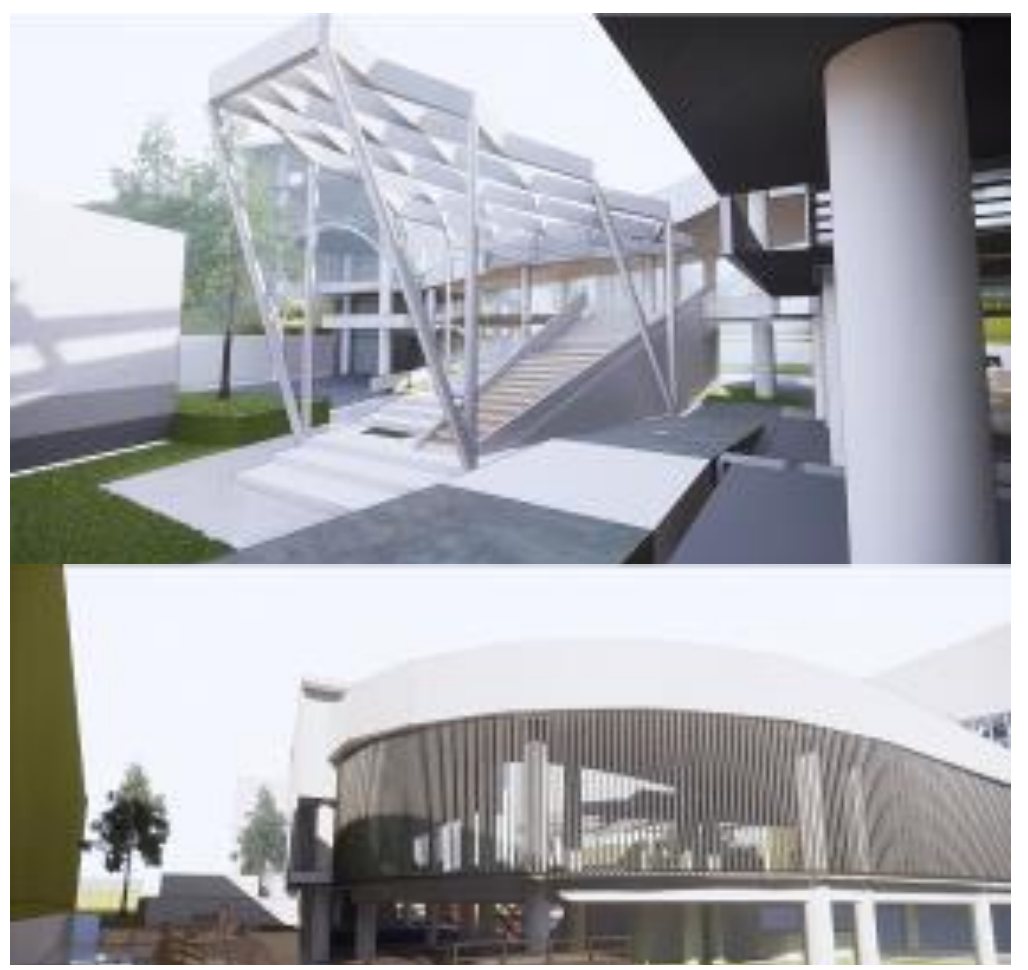

Gambar 3. Perspektif Eksterior Bangunan Sumber: Penulis, 2019 
Disamping keterkaitannya terhadap cara hidup yang materialis, perlu dipahami bahwa tingginya minat masyarakat dalam menjadikan budaya barat dan eksistensinya sebagai tolak ukur dihasilkan dari keinginan untuk melawan stigma masyarakat ketimuran terhadap kehidupan yang seragam. Tren berpakaian yang eksentrik dan terbuka maupun minat terhadap film-film avant garde yang absurd mengembalikan rasa keperluan untuk menjadi pribadi berkarakter dan istimewa. Kehadiran "Budaya Populer" atau disebut juga dengan "Budaya Pop" ditengah-tengah masyarakat kita tanpa disertai dengan filter pengetahuan, pemahaman, dan kesadaran diri terhadap nilai budaya sendiri membawa dampak besar terhadap keberadaan kebudayaan setempat yang menurut kesesuaian karakter masyarakat memiliki nilai-nilai luhur. Tergesernya budaya setempat dari lingkungannya sendiri, disebabkan oleh kemunculan sebuah kebudayaan baru (pop-culture) yang didukung oleh putra-putrinya sendiri dan konon sebagai alasannya dianggap lebih atraktif, fleksibel dan mudah dipahami meskipun berlawanan dengan nilai kebudayaan setempat sehingga mendapat perilaku diskriminatif dari sekitarnya.

Bias menuntut masyarakat untuk bersikap secara conformity atau keseragaman dikarenakan oleh keadat-istiadatan, agama, maupun kombinasi dari keduanya. Conformity merupakan paham ataupun ideologi yang dianut dan dijunjung oleh bermacam institusi seperti institusi pendidikaan dan korporasi. Meskipun memiliki beberapa nilai yang dianggap positif,

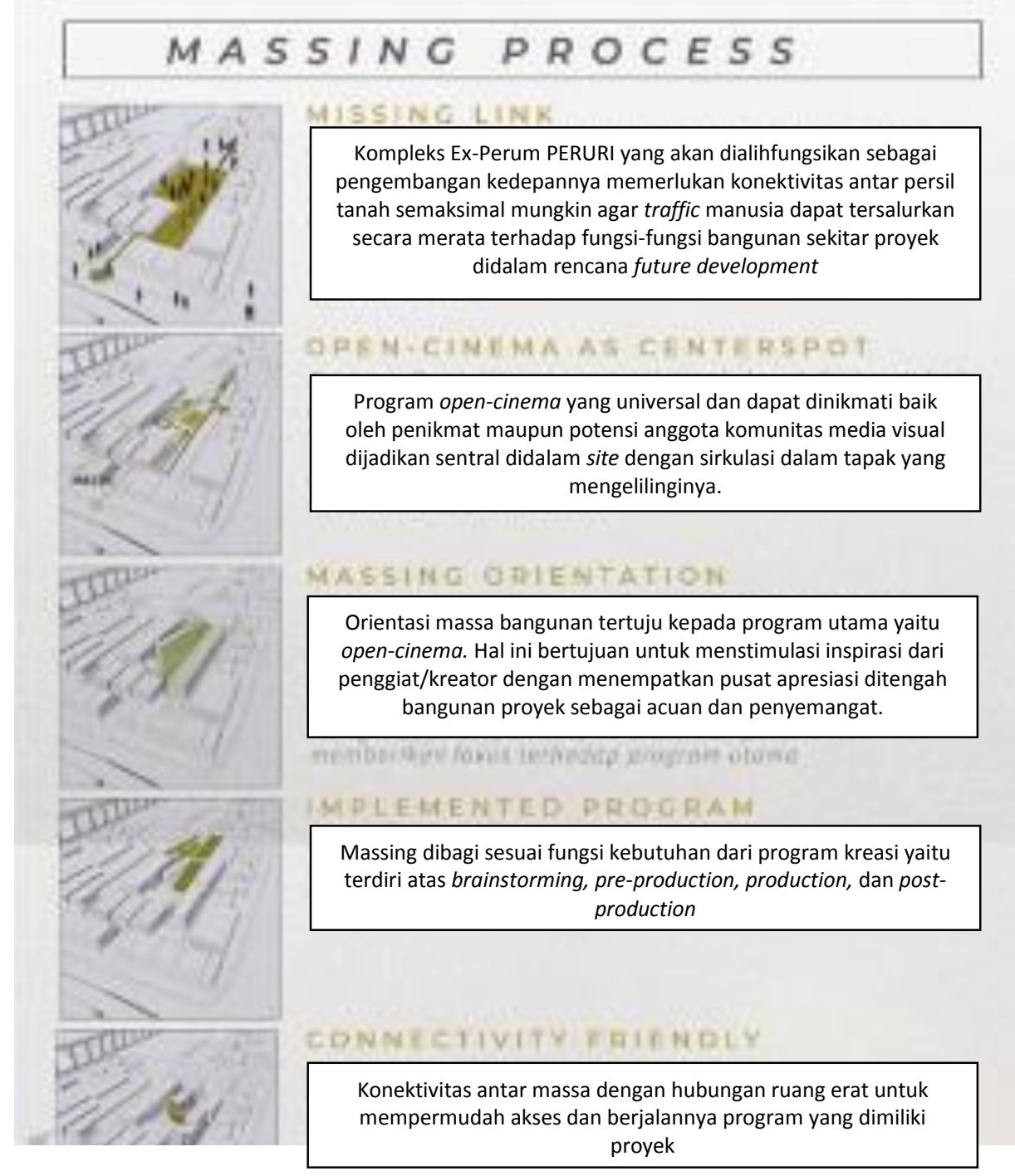

Gambar 4. Proses Pembentukan Gubahan Massa

Sumber: Penulis, 2019 
paham conformity yang ekstrim memberikan pengaruh negatif terhadap pembentukan karakter dan menyebabkan hilangnya jati diri bagi beberapa individu terkait. Dasar utama dari conformity adalah ketika individu memiliki tendensi yang kuat untuk melakukan sesuatu yang sama dengan kelompoknya walaupun tindakan tersebut tidak sesuai dengan dirinya ${ }^{5}$. Salah satu alasan penting mengapa seseorang melalukan conformity adalah sesorang belajar bahwa dengan melalukannya, hal tersebut dapat membantunya untuk mendapat persetujuan dan penerimaan yang diinginkan. Filsuf Spencer menyatakan bahwa asas egoisme, atau asas 'mendahulukan kepentingan diri sendiri di atas kepentingan orang lain" mutlak diperlukan oleh mahkluk hidup untuk dapat bertahan di tengah alam yang kejam. Sikap egois membuat makhluk menjadi kuat, sehingga ia cocok dengan alam untuk dapat bertahan hidup langsung. Asas altruism ini sengatlah berpengaruh terhadap manusia karena manusia merupakan makhluk yang hidup secara kolektif. Hal inilah yang memberatkan masyarakat untuk membatasi bentuk ekspresi yang ekstrim guna menghindari perilaku diskriminatif dari masyarakat. Fenomena ini menempatkan manusia dibawah tekanan dari pihak lain untuk bersikap sewajarnya-wajarnya dengan membatasi kebebasan seorang individu untuk berekspresi dan menjadi dirinya sendiri.

Dasar inilah yang membuat perancang mengusung konsep Kreasi dan Apresiasi dimana proyek dimaksudkan sebagai wadah berekspresi masyarakat tanpa menerima diskriminasi dari kaum tertentu, terutama pada program yang meliputi ranah media visual. Konsep ini diaplikasikan terhadap pembentukan massa bangunan yang memudahkan program itu untuk berjalan semaksimal mungkin.

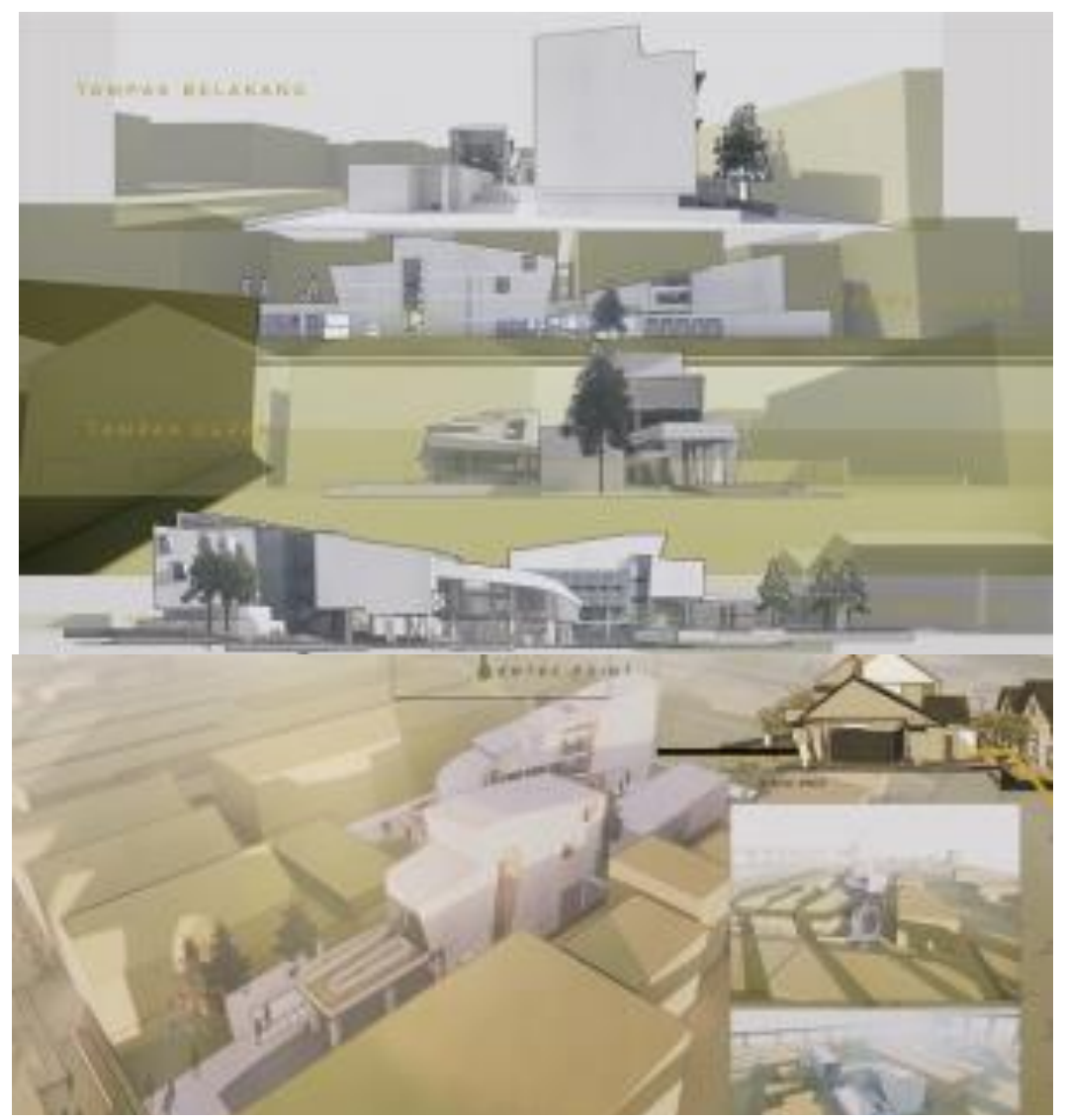

Gambar 5. Gambaran perancangan proyek Sumber: Penulis, 2019

\footnotetext{
${ }^{5}$ Maksyur, Siswati (2011). Hubungan konsep diri dengan konformitas terhadap kelompok teman sebaya pada aktivitas clubbing. Studi korelasi. Bandung: Universitas Padjajaran.
} 


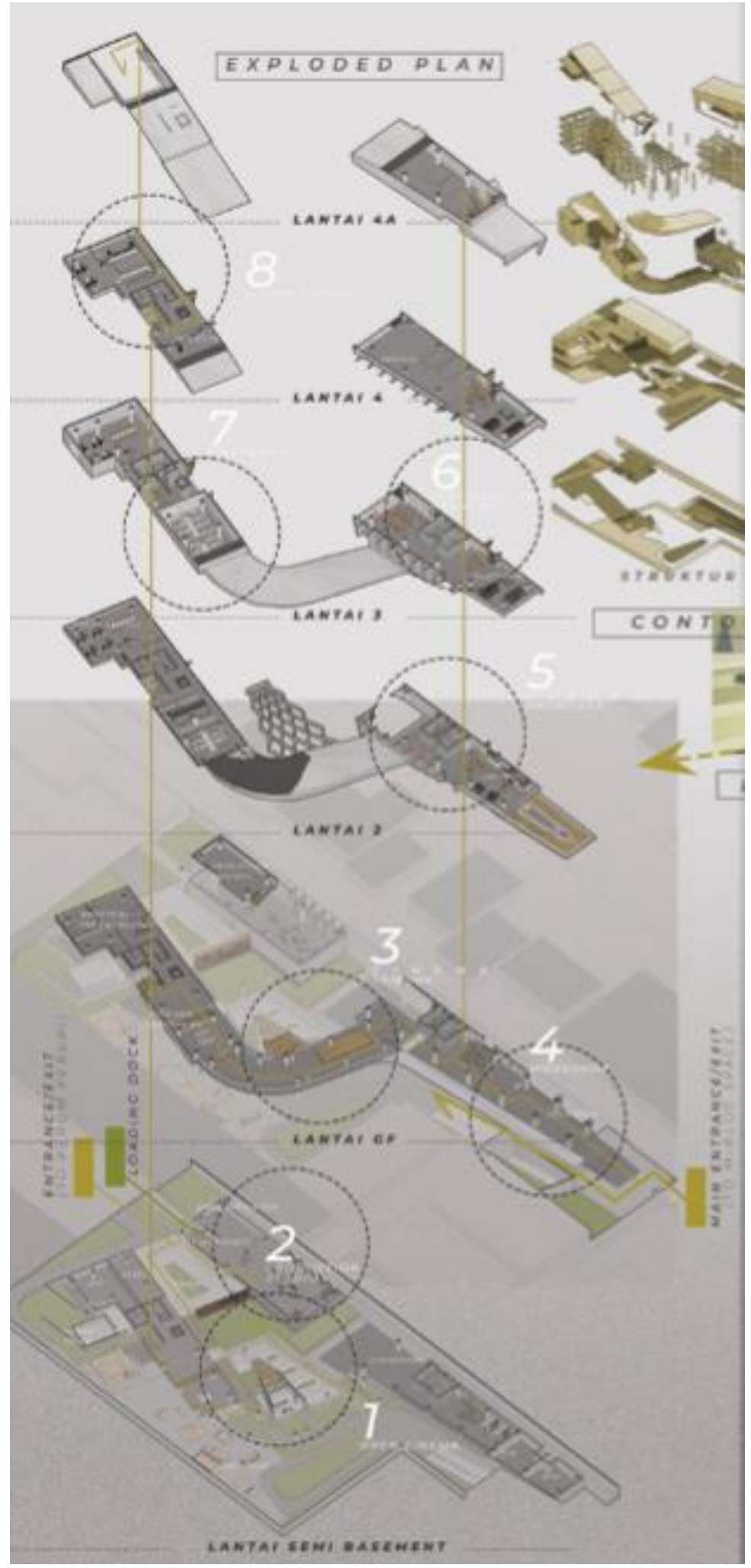

Gambar 6. Exploded Plan Proyek yang Menggambarkan Denah Keseluruhan Sumber: Penulis, 2019 


\section{KESIMPULAN DAN SARAN}

Kebutuhan masyarakat atas third space harus dapat dipenuhi melalui pertimbangan dari fenomena-fenomena yang terjadi pada kawasan tersebut. Pada kasus kawasan Melawai, merupakan fenomena peleburan antara budaya asing dengan budaya lokal dan pengaruh yang ditimbulkannya terhadap masyarakat sekitar yang dijadikan potensi untuk mempersatukan kembali masyarakat tersebut. Dengan menyesuaikan dengan kebutuhan non-sosial maupun sosial masyarakat, third place yang diciptakan oleh proyek dapat berkontribusi secara penuh dalam meningkatkan kesejahteraan masyarakat secara ekonomi, ekudasi, maupun budaya.

Selain berfungsi sebagai ruang sosial, proyek Studio Media Visual dan Sinema Ruang Luar merangkap sebagai wadah kreatif yang dapat menjadi sebuah katalis yang memperbaiki kualitas hidup masyarakat Melawai. Inklusivitas yang dimiliki proyek, yang dibuat dengan mempertimbangkan aksesibilitas dari kaum masyarakat dengan kebutuhan khusus, mengembalikan kebersamaan masyarakat kedalam suatu kesatuan yang beragam, namun penuh dengan toleransi.

Simbiosis yang tercipta dari komunitas, baik bagi kontributor kreatif maupun sebagai penikmat karya (apresiator), melalui program dan ruang yang diciptakan, dapat mencapai misi proyek yang berupa kreasi dan apresiasi terhadap karya lokal, peningkatan potensi calon pekerja industri kreatif media visual maupun perfilman, peningkatan konseptualitas karya, memperkuat ikatan antara berbagai macam kelas masyarakat, dan aplikasi konsep hiburan baru yang inklusif dan tidak komersil.

Adapun juga saran dari perancang yang disimpulkan berdasarkan proses pembelajaran selama perancangan proyek ialah bahwa proyek kedepannya harus dapat menyesuaikan rancangan terhadap generasi yang berperan besar, di kawasan tersebut, pada era tersebut. Tujuan utamanya adalah untuk menciptakan proyek yang tidak lekang dimakan zaman, sehingga dimasa depannya dapat ditambah maupun dikembangkan fungsinya, namun tidak mengalami perubahan secara total sehingga dapat fleksibel digunakan oleh generasi pada masanya, maupun dimasa yang akan datang

\section{REFERENSI}

Alexander, C (1977). A Pattern Language: Towns, Buildings, Constructions. California: Oxford University Press

Ching, D.K., F., (2008). Arsitektur Bentuk, Ruang dan Susunannya. Jakarta: Penerbit Erlangga

McLaren, D. (2015). Sharing Cities: A Case for Truly Smart and Sustainable Cities. Cambridge: MIT Press

Neufert, E. (1997), Data Arsitek Jilid 1 Edisi 33, Terjemahan Sunarto Tjahjadi. Jakarta: Penerbit Erlangga

Neufert, Ernst, (1997), Data Arsitek Jilid II Edisi 33, Terjemahan Sunarto Tjahjadi. Jakarta: Penerbit Erlangga

Oldenburg, R. (1989). The Great Good Place: Cafes, Coffee Shops, Community Centers, Beauty Parlors, General Stores, Bars, Hangouts, and How They Get You Through the Day. New York: Paragon House.

Picon, A. (2015). Smart Cities: A Spatialised Intelligence. America Serikat: Paperback

Picard, Q. (2002) Architect Hand book, United Kingdom: Blackwell Science Ltd.

Snyder, J. C.\& Catanese, A. J. (1989) Pengantar Arsitektur, Jakarta: Erlangga.

Tschumi, B. dan Walkers, E. (2006). Tschumi on Architecture: Conversations with Enrique Walkers. Monacelli, November 2006

WJS Poerwadarminta, (1976), Kamus Umum Bahasa Indonesia, Jakarta: Balai Pustaka. 
